\title{
An assessment of the effect of hull girder vibration on the statistical characteristics of wave loads
}

\author{
Yoshitaka Ogawa $^{1}$ and Ken Takagi ${ }^{2}$ \\ ${ }^{I}$ National Maritime Research Institute, Japan, Mitaka,Tokyo, Japan \\ ${ }^{2}$ Dept. of Environmental \& Ocean Engineering, The University of Tokyo Chiba, Japan
}

\begin{abstract}
For the assessment of statistical characteristics of wave loads in the real sea state, the probability distribution of wave loads are computed based on the sufficient duration of computations in irregular waves. First of all, the estimation of wave impact loads is well modified applying the displacement potential formulation, which was proposed by one of authors, for solving Wagner's flow model. Consequently, the present computation method is also modified. Prior to the computation in irregular waves, preliminary computation to determine the adequate number of realization of irregular waves is examined.

The effect of hull girder vibration on the statistical characteristics is examined by means of the computation with/without hull girder vibration. It is found that hull girder vibration has a certain effect on the probability of occurrence of wave loads. Furthermore, computations taking account of the effect of operation, that is the effects of ship speed and course change, is conducted for the rational evaluation of the effects of hull girder vibration. It is clarified that the effect of operation on the statistical characteristics of wave loads is significant. It is verified that the evaluation without the effect of operation may overestimate the effect of hull girder vibration.
\end{abstract}

KEY WORDS: Wave loads; Nonlinearity of ship motion; Hull girder vibration; Nonlinear strip theory; The effect of operation; Large container ship.

\section{INTRODUCTION}

Because recent ships get longer and faster, the effect of nonlinearity of ship motion and the hydroelastic effects become more significant. For example, the number of large container ship has been increasing in recent years. A large bow flare and an overhanging stern of a large container ship greatly effect on nonlinear ship motions and nonlinear wave loads. Consequently, wave-induced extreme loads, i.e. bending moment and shear force, could increase and the fatigue life of the ship structure could be decreased. Therefore, it is important to examine wave-induced design loads and the fatigue damage taking account of those dynamic effects.

Based on this background, authors developed the prediction method for the estimation of nonlinear ship motion and wave loads in irregular waves without waste of huge computation time. The present method was developed based on the nonlinear strip method approach (Bishop et al., 1977; Jensen, 1979; Yamamoto, 1980; Fujino, 1983; ISSC, 2000)

Corresponding author: Yoshitaka Ogawa

e-mail: ogawa@nmri.go.jp because many simplified approaches have been utilized to meet the need of ship design.

In the present study, firstly, the present method is verified through the comparison with measured wave loads in the model experiments. Particularly, the accuracy of wave impact pressure is well modified applying the displacement potential formulation, which was proposed by one of authors, for solving Wagner's flow model. Consequently, the accuracy of computation of wave loads is also modified.

Secondly, the effect of hull girder vibration on the statistical characteristics is examined by means of the computation with/without hull girder vibration. It is found that hull girder vibration has a certain effect on the probability of occurrence of wave loads. It is important to consider the effect of hull girder vibration on the statistical characteristics of wave loads.

However, in the real navigation, ship speed is reduced owing to the nominal speed loss and deliberate speed loss. Particularly, those speed loss become significant in rough seas because ship motion and wave loads become large. In addition to this, in the real navigation, ship course are changed to avoid severe condition particularly in rough seas. In the meanwhile, conventional computations for the evaluation of statistical characteristics of ship motion and 
wave loads are generally conducted under the assumption that ship speed and course are constant. Therefore, this implies that computation and model experiments taking the account of the effect of operation should be conducted.

Finally, the relation of ship speed and course with the statistical characteristics of wave loads is examined through the computation with the reduction of ship speed and the course change when the ship motion becomes significant. It is clarified that the probability with speed reduction or course change becomes smaller than that with constant ship speed and course. It is clarified that the evaluation without the effect of operation may overestimate the effect of hull girder vibration on wave loads.

\section{NUMERICAL MODEL UTILIZED IN THE PRESENT STUDY}

Ship motions and wave loads are computed by means of the time domain simulation program, developed by the National Maritime Research Institute of Japan (Ogawa, 2005). The program, namely NMRIW (Nonlinear Motion in Regular and Irregular Waves), is based on a nonlinear strip method (Bishop et al., 1977; Jensen, 1979; Yamamoto, 1980; Fujino, 1983; ISSC, 2000). The NMRIW was developed reflecting the latest results of a seakeeping and maneuvering study (Hamamoto, 1993). Forces due to linear and nonlinear potential flow are combined with maneuvering forces and viscous drag forces. It is well known that it is difficult to compute nonlinear wave loads in bow and quartering seas by means of the existing time domain computation method. Using the present method, wave loads in bow and quartering seas can be estimated rationally.

Ship motion components, $X_{j}(j=1,2 \ldots, 6)$, are determined from a set of 6 differential equations of motion with its origin at the centre of gravity. Here $j=1,2,3,4,5,6$ refer to surge, sway, heave, roll, pitch and yaw modes, respectively. With respect to rotations, a right-handed convention is used. The equations of motion for a ship traveling with forward speed $U$ are described as

$$
\begin{aligned}
& \left(\mathbf{M}_{i j}+\mathbf{A}_{i j}\right) \ddot{\mathbf{X}}_{j}+\mathbf{B}_{i j} \dot{\mathbf{X}}_{j}+\mathbf{C}_{i j} \mathbf{X}_{j}=\mathbf{F}_{j}^{W}+\mathbf{F}_{j}^{V} \\
& i, j=1,2,3,4,5,6
\end{aligned}
$$

where $\ddot{\mathbf{X}}_{j}$ and $\dot{\mathbf{X}}_{j}$ denote motion acceleration and velocity, respectively. $\mathbf{M}_{\mathbf{i j}}$ and $\mathbf{A}_{\mathbf{i j}}$ denote mass and added mass respectively. $\mathbf{B}_{\mathbf{i j}}$ denotes damping. $\mathbf{C}_{\mathbf{i j}}$ denotes the restoring coefficient. The index, $i$, denotes the direction of the fluid force. $\mathbf{F}_{\mathbf{j}} \mathbf{W}^{\mathbf{W}}$ denotes the wave exciting force. $\mathbf{F}_{\mathbf{j}} \mathbf{V}^{\mathbf{V}}$ denotes the excitation force due to viscous effects.

In terms of global flexible modes, the modal superposition approach is applied in accordance with formulation by Yamamoto et al(Yamamoto, 1980). Equations of motion including flexible modes are solved in the time domain by means of a 4th-order Runge-Kutta scheme. The
Froude-Krylov force, which has considerable effect on the nonlinearity of ship motions, is estimated by the integration of the hydrostatic and hydrodynamic wave pressure along the instantaneous wetted surface of the hull at each time step.

With respect to the sectional wave radiation force and potential value at each time step, the integral equation method is utilized. Source and doublet are distributed at the origin of each section to avoid the irregular frequency, in accordance with Ohmatsu's method (Ohmatsu, 1975). The sectional diffraction force, in the present method, is computed by solving the Helmholtz equation at each time step.

Wave impact load due to slamming is computed by means of the displacement potential approach (Takagi, 2007; Ogawa, 2009) in terms of the instantaneous wetted surface at each time step.

The viscous effect of roll damping due to ship hull and bilge keels is estimated using various empirical formulae. The propeller thrust is described by means of the propeller characteristics. The hull resistance is a function of the instantaneous speed and draft. Lateral force and yaw moment due to rudder is considered to keep a target course $\psi_{0}$ for the ship in the simulation. The rudder is controlled by the PID control as follows:

$$
\begin{aligned}
& \delta=-K_{P} e+K_{I} \int_{0}^{t} e d t+K_{D} \frac{d e}{d t} \\
& e=\psi-\psi_{0}
\end{aligned}
$$

where $\delta$ denotes the rudder angle. $e$ denotes the deviation of the ship course. $\psi$ and $\psi_{0}$ denote the instantaneous course and target course respectively. $K_{P}, K_{I}$ and $K_{D}$ denote the proportional gain, integral gain and differential gain, respectively.

The sea surface and wave kinematics are described based on the linear wave theory. The sea surface of irregular waves is described by the linear superposition of regular waves with random phase angles.

\section{VALIDATION OF THE COMPUTATION THROUGH THE COMPARISON WITH EXPERIMENTAL DATA}

\section{Comparison with experiments of the large container ship}

Present computation method had been verified through the comparison with model experiments of many kinds of ship in various wave conditions. The results of those validation of the computation method had been published (Ogawa, 2005\& 2007; Oka, 2009). Based on the validation, it was clarified that computed wave loads basically gives ample agreement with experiments. It was also clarified that there are some rooms for modification in the computation of wave impact loads, which is the trigger for whipping vibration.

Therefore, authors revised the computation of wave impact loads applying the displacement potential approach 
(Takagi, 2007; Ogawa, 2009) in terms of the instantaneous wetted surface at each time step. Here, the example of the computation of wave vertical bending moment in terms of the post-panamax container ship is shown.

Prior to the comparison with experiments, the section relevant to the following results in this study is repeated here because detailed explanation of experiments has been published (Ogawa et al., 2007).

A series of seakeeping tests in waves by means of the model of a post-panamax container ship was performed to measure wave loads on the hull. The tests were conducted at the Square Basin $(160 \mathrm{~m} \times 30 \mathrm{~m})$ of the Mitsubishi Heavy Industries, Ltd. Table 1 presents the ship's main particulars. Before the test, the model was ballasted to the correct draft, trim and the GM. The model was divided into 4 parts to measure wave loads at S.S.2.5, S.S.5 and S.S.7.5. The weight distribution of the container ship was arranged to be similar with that of an actual container ship.

The spring, of which natural frequency is adequately smaller than wave encounter frequency of present experiments, was attached on the gravity dynamometer to produce restoring forces of a plane motion. Ship motions were measured by means of potentiometer and Fiber-Optic Gyro. Vertical acceleration was measured at F.P. by means of an accelerometer. Wave bending moment (vertical and lateral), wave shearing force (vertical and lateral) and wave induced torsional moment were measured at S.S.2.5, S.S.5 and S.S.7.5, by means of Force transducers.

Table 1. Principle particulars of the large container ship

\begin{tabular}{|c|c|c|}
\hline & Ship & Model \\
\hline Length $(\mathrm{Lpp})(m)$ & 283.8 & 5.0 \\
\hline Breadth $(\mathrm{B})(m)$ & 42.8 & 0.754 \\
\hline $\operatorname{Draft}(\mathrm{d})(m)$ & 14.0 & 0.274 \\
\hline GM $(m)$ & 1.08 & 0.019 \\
\hline $\begin{array}{c}\text { Longitudinal radius of gyration } \\
(\kappa y y / L p p)\end{array}$ & --- & 0.243 \\
\hline
\end{tabular}

A series of tests in regular and irregular waves was carried out to allow a comparison with an analytical study. Experiment in regular waves was carried out in head $(180 \mathrm{deg}$.) and bow (150deg. and 120deg.) seas. The mean ship speed in waves was set at 24.5 knots (Froude number $=0.239$ ), which is a service speed of this post-panamax container ship, and 18.4 knots (Froude number $=0.179$ ). Experiments were carried out in various wave heights $(3.5$ and $9 \mathrm{~m})$. In the case of 18.4 knots, experiments in $15 \mathrm{~m}$ wave height were also carried out. Wave length was also varied in the experiments.

Tests in irregular waves were also carried out in head (180 deg.) seas with various significant wave heights $(3.5 \mathrm{~m}$, $7.0 \mathrm{~m}$ and $12.5 \mathrm{~m}$ ). The ISSC spectrum was used for a wave spectrum of irregular waves. The mean wave period, $\underline{T}_{02}$, was 11.4 seconds. This corresponds to a severe condition for the ship's longitudinal motion and wave loads. The mean ship speed in waves was set at 18.4 knots $(F n=0.179)$, which takes into account the nominal and derivative speed loss.
Fig. 1 shows the example of the time history of vertical bending moment at midship and S.S.7.5. It is also found that two-node vibration owing to the whipping occurs with natural frequency of the present container ship. It is clarified that the present method can execute the robust computation of wave loads including whipping vibration.

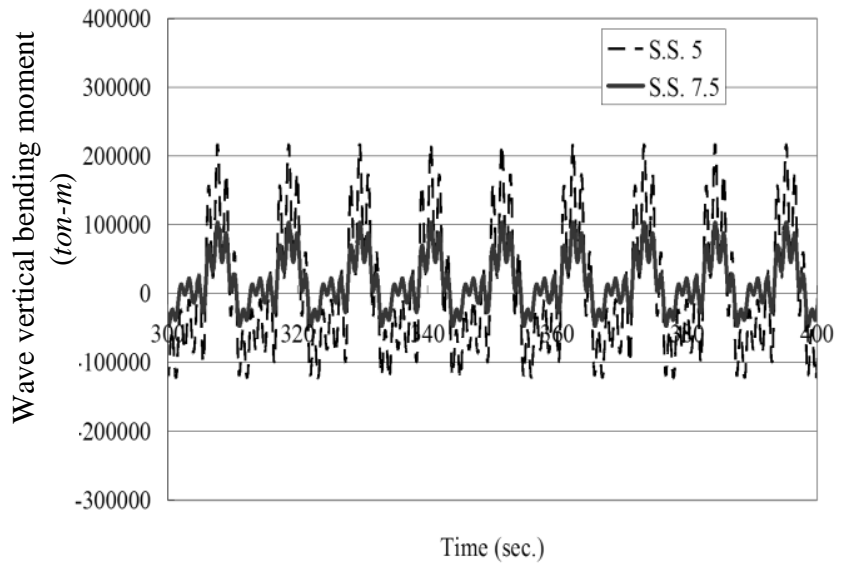

Fig. 1 Time history of the wave vertical bending moment of the post-panamax container ship at S.S.7.5 and S.S.5 $(\chi=180$ deg., $F n=0.219, H w=9 m, \lambda / L=1.0$ )

Fig.2 shows example of validation for the wave vertical bending moment in head seas. The peak value of wave vertical bending moment, $M v$, is divided by $\rho g \zeta B L^{2}$. Here, $\rho$ and $g$ describe the density of fluid and acceleration of gravity, respectively. $\zeta, B$ and $L$ describe wave amplitude, ship breadth and ship length, respectively. For the comparison, computation by means of the former computation (Ogawa, 2007) and the computation in small wave height that correspond to the linear computation.

It is found that the present computation gives ample agreement with experiments. It is clarified that the present method can explain the experiments more rationally than those of former computation and linear computation.

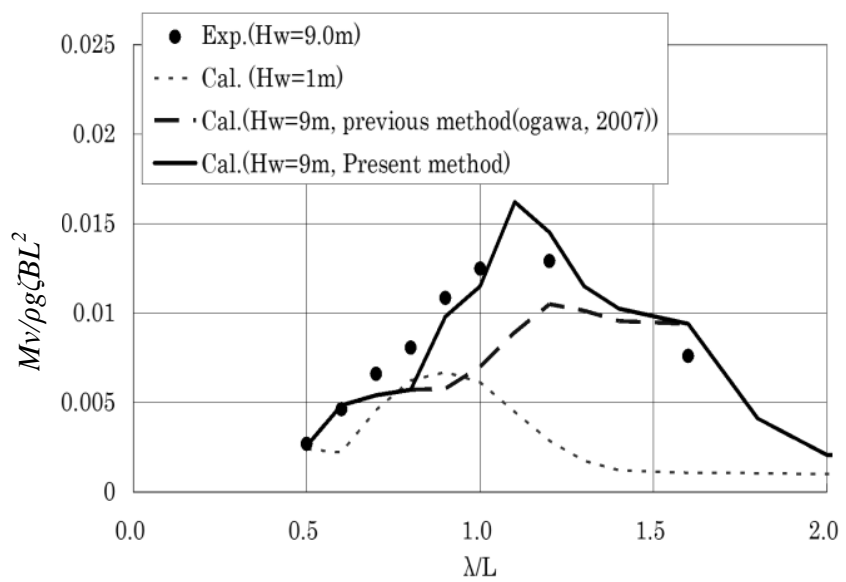

Fig. 2 The response amplitude operator of the wave vertical bending moment of the post-panamax container ship at S.S.7.5 ( $\chi=180$ deg., $F n=0.219$ ) 


\section{COMPUTATION OF PROBABILITY OF OCCURRENCE OF WAVE LOADS IN IRREGULAR WAVES}

\section{Computation in Irregular Waves}

Incident wave was realized by the sum of 200 components of waves in accordance with the Jonswap spectrum. To obtain the stable results, 10 times simulations with the duration of 3600 seconds of ship scale were carried out in each condition. The combination of phase angle of each wave component was varied in each simulation. Fig. 3 shows the example of the spectrum of incident wave. It is found that the planed spectrum, which is shown as "Base", is the same as the computed spectrum, which is derived from the time history of computed incident wave and is shown as "Cal.". It is found that present computation method can adequately realize the wave spectrum, which is the basis for the utilization of direct computation for the clarification of statistical value of ship response in waves.

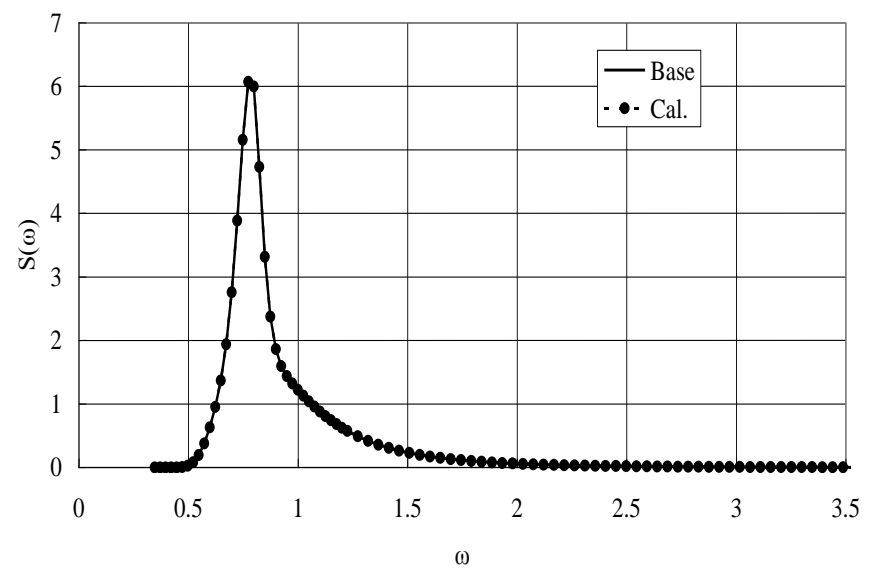

Fig. 3 The example of spectrum of incident wave (significant wave height: $5 m$, mean wave period: $8.0 \mathrm{sec}$.)

In terms of the computation in irregular waves, postpanamax container ship, which is shown in previous section, is used. Fig. 4 shows the example of the probability density function of pitch and roll amplitude. The horizontal axis denotes the pitch and roll angle. Dotted lines show the approximation of Gaussian distribution of those computed probability density function. It is found that the probability density function of the computed pitch amplitude of 10 times simulations with the duration of 3600 seconds can be approximated by the Gaussian distribution. However, it is also found that the probability density function of the computed roll amplitude of the subjected post-panamax container ship is much different from the Gaussian distribution due to nonergodic nature of parametric roll although a certain distribution can be approximated.

Fig. 5 shows the example of the time history of vertical bending moment. It is found that the hull girder vibration owing to the whipping occurs frequently in such a severe sea state. It is also found that two-node vibration occurs with natural frequency of the present container ship. It is clarified that the present method can execute the robust computation in a sever sea state with a long term duration.

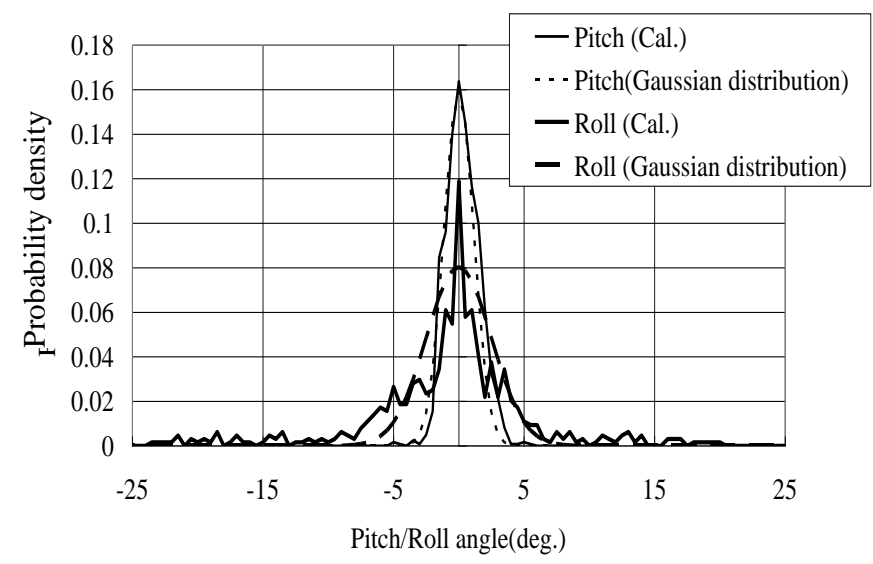

Fig. 4 The probability density function of pitch and roll amplitude $(\chi=180 \mathrm{deg}$., $F n=0.055$, mean wave period: 12.0 sec., significant wave height: $9.5 \mathrm{~m}$ )

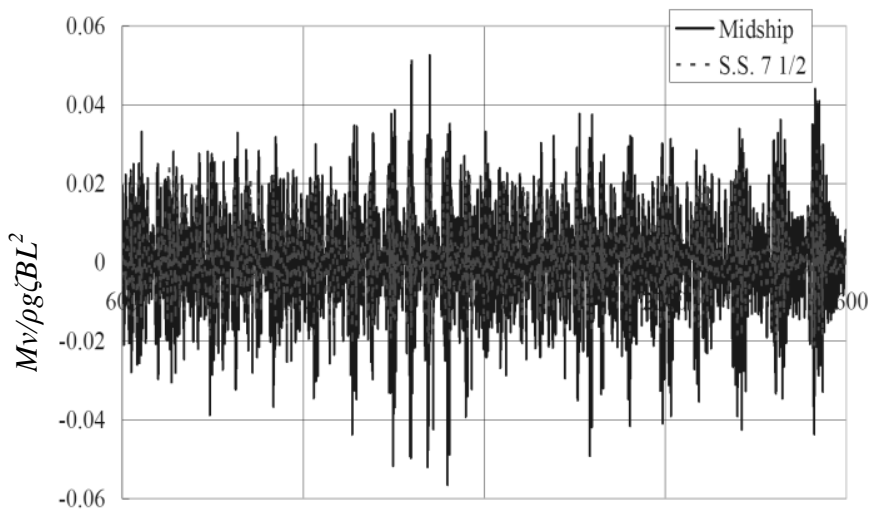

$\mathrm{t}(\mathrm{sec}$.

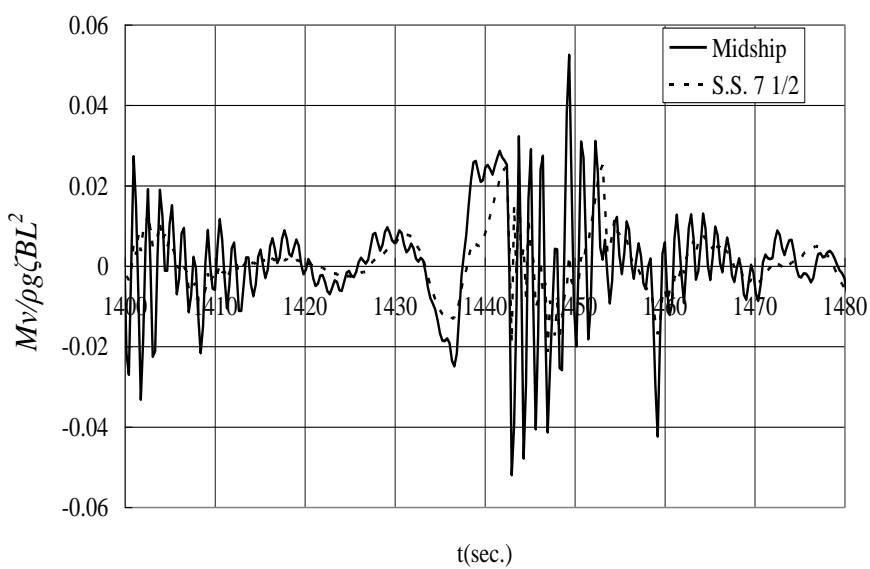

Fig. 5 The example of time history of wave vertical bending moment $(\chi=180$ deg., significant wave height: $10 \mathrm{~m}$, mean wave period: 15.0sec.) (Below: magnification of above time history of 2000second within one hour duration) 
The Relation of Ship Speed with the Probability of Occurrence in Short Term Sea State

Fig. 6 shows the relation of speed reduction with the probability of wave vertical bending moment. This probability is derived from the histogram of the computed sagging moment. The value of horizontal axis denotes the nondimensional value divided by $\rho g \zeta B L^{2}$ (in this case, $\zeta$ is the significant wave amplitude). The solid line in Fig. 6 shows the probability of occurrence without speed reduction. This means that computation is carried out with constant ship speed. For the evaluation of the effect of hull girder vibration, wave loads taking only rigid motion into account is computed in the same irregular waves. This computation derives the wave loads without hull girder vibration. The probability of wave loads computed without hull girder vibration is also shown in Fig. 6 as the small dotted line.

Although the number of peak value is different owing to the hull girder vibration, it is found that hull girder vibration has a certain effect on the probability of occurrence of wave loads. It is clarified that it is important to consider the effect hull girder vibration on the statistical characteristics of wave loads.

However, in the real navigation, ship speed is reduced owing to the nominal speed loss and deliberate speed loss. Particularly, those speed loss become significant in rough seas because ship motion and wave loads become large. In addition to this, in the real navigation, ship course are changed to avoid severe condition particularly in rough seas. In the meanwhile, usual computations for the evaluation of statistical characteristics of ship motion and wave loads have been generally conducted under the assumption that ship speed and course are constant. Therefore, it is inadequate to assess the effect of hull girder vibration on wave loads quantitatively based on the computation and the model experiments with constant ship speed and course. This implies that computation and model experiments taking the effect of operation should be conducted.

Using the present computation method, the probability of occurrence with speed reduction is computed. It is shown as the dotted line in Fig. 6. In this computation, ship speed was reduced to two third of initial ship speed when the pitching motion becomes large in the computation.

It is found that the probability with speed reduction becomes smaller than that without speed reduction because the whipping induced hull girder vibration is significantly reduced owing to the speed reduction. It is clarified that the evaluation without the effect of operation may overestimate the effect of hull girder vibration on statistical characteristics of wave loads quantitatively.

Fig. 7 shows the example of the computed probability of occurrence of wave vertical bending moment with various ship speeds. This probability is derived from the histogram of the computed sagging and hogging moment separately. It is found that the occurrence probability of sagging moment is slightly different from that of hogging moment because the effect of hull girder vibration and nonlinearity of ship motion are not significant in $5 \mathrm{~m}$ wave height. In the meanwhile, it is clarified that the effect of ship forward speed on the probability is significant. In the real navigation, criteria for the speed loss and the course change are based on not only hull girder vibration but also large motion and acceleration. This implies that the statistical characteristics of wave loads should be also evaluated in various wave conditions that hull girder vibration doesn't occur.

Based on the results in Fig. 6 and 7, it is verified that the setting of ship speed has much effect on the probability. Therefore, it is considered that further quantitative examination of the degree of speed reduction is required in the future study. Particularly, the relation of the criteria for the speed loss and the course change with statistical characteristics of wave loads should be examined further although it is clarified that the direct computation can explain the effect of speed reduction on the probability rationally.

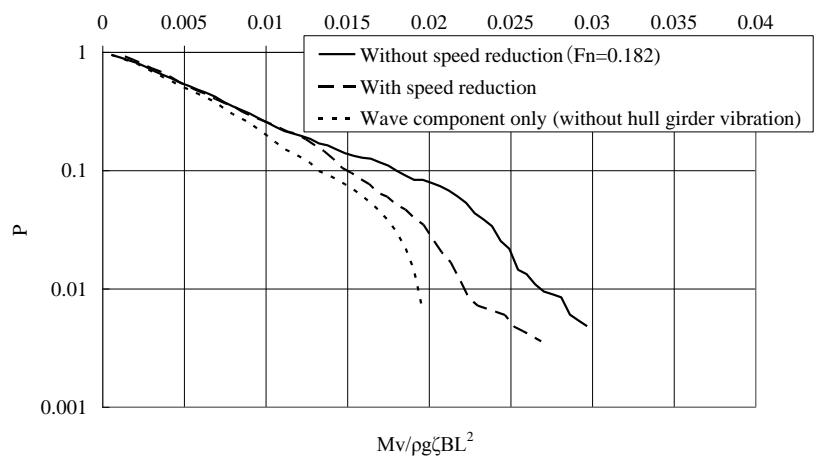

Fig. 6 The relation of ship speed with the probability of occurrence of wave vertical bending moment at midship $(\chi=180$ deg., significant wave height: $10 \mathrm{~m}$, mean wave period: $15.0 \mathrm{sec}$.)

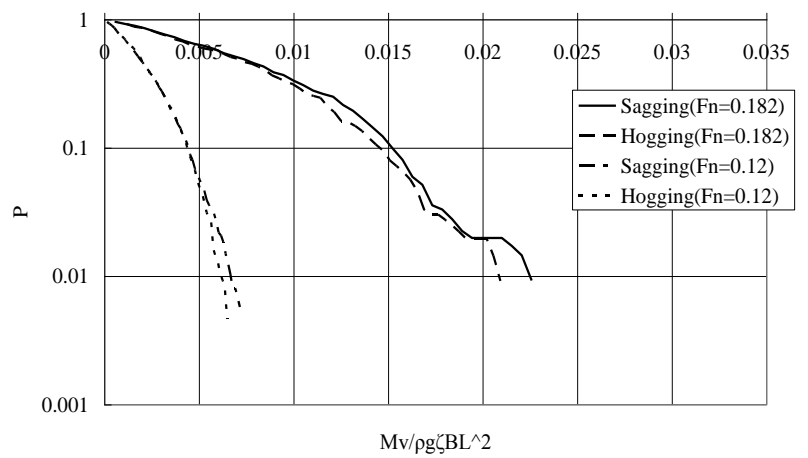

Fig. 7 The effect of ship speed on the probability of occurrence of wave vertical bending moment at midship $(\chi=180 \mathrm{deg}$, , significant wave height: $5 \mathrm{~m}$, mean wave period: 15.0sec.)

The Relation of Wave Encounter Angle with the Probability of Occurrence in Short Term Sea State

Fig. 8 shows the relation of course change with the probability of wave vertical bending moment. The solid line in Fig. 8 shows the probability of occurrence without course change. This means that computation is carried out with constant headings. In the meanwhile, the dotted line shows the probability of occurrence with course change. In this 
computation, heading angle was varied from head seas (180 deg.) to bow quartering seas (170 deg.) when the pitching motion becomes large in the computation. It is found that the probability with course change becomes smaller than that without course change because the whipping induced hull girder vibration is certainly reduced owing to the course change. It is clarified that the direct computation can explain the effect of course change on the probability rationally.

In addition to them, probability of wave loads at bow seas (170 deg.) computed without course change is also computed. This is shown as the small dotted line in Fig. 8. Although the resulting heading is same as bow seas (170 deg.), it is found that the probability at bow seas is different from that with course change in head seas. It is clarified the evaluation of statistical characteristics of wave loads with constant course may be different from the real situation. Therefore, it is important to compute wave loads taking the effect of course change into account.

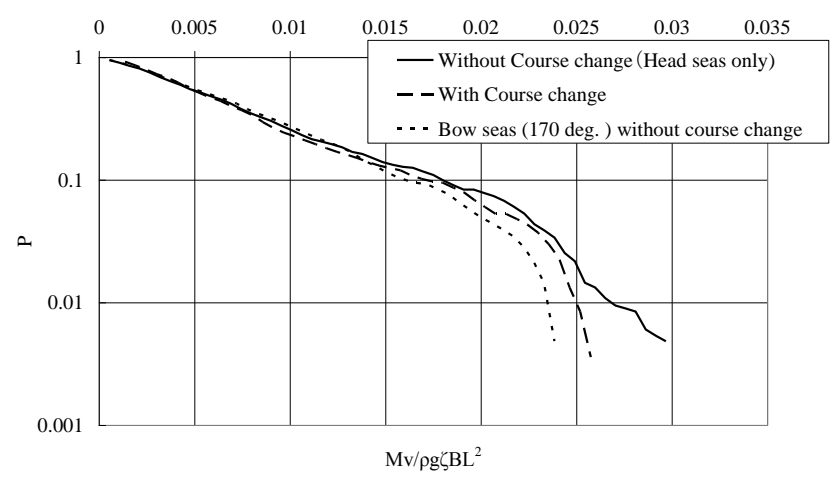

Fig. 8 The relation of wave encounter angle with the probability of occurrence of wave vertical bending moment at midship $(\chi=180$ deg., significant wave height: $10 \mathrm{~m}$, mean wave period: $15.0 \mathrm{sec}$.)

\section{CONCLUSIONS}

Through the computation of wave loads in irregular waves, the effect of hull girder vibration on the statistical characteristics of wave loads is examined. Conclusions are as follows:

1) The accuracy of computation of wave loads is modified by applying the displacement potential formulation for the estimation of wave impact loads.

2) The hull girder vibration has a certain effect on the probability of occurrence of wave loads.

3) In the meanwhile, for the rational consideration of the effect of hull girder vibration, the effect of operation on the statistical characteristics of wave loads should be considered. It is verified that the evaluation without the effect of operation may overestimate the effect of hull girder vibration.

\section{ACKNOWLEDGEMENTS}

A part of the present study was supported by a Grant-in Aid for Scientific Research of the Japan Society for Promotion of Science (No. 20360400).

\section{REFERENCES}

Bishop, R.E.D. Price, W.G. and Tam, P.K.Y., 1977. A unified dynamic analysis of ship response to waves, Transaction of Royal Institute of Naval Architects, London, UK. Vol.119, pp.363-390.

Fujino, M. and Chiu, F., 1983. Vertical Motions of High-speed Boats in Head Sea and Wave Load. Journal of the Society of Naval Architecture of Japan, 154, pp. 151-163.

Hamamoto, M. and Kim, Y.S., 1993. A New Coordinate System and the Equations Describing Manoeuvring Motion of Ship in Waves, Journal of the Society of Naval Architecture of Japan, 173, pp. 209-220.

ISSC, 2000. Extreme hull girder loading, special task committee VI.1, $14^{\text {th }}$ international ship and offshore structures congress, Nagasaki, Japan, pp. 263-320.

Jensen, J.J. and Pedersen, P.T., 1979. Wave-induced bending moments in ships - a quadratic theory. Transaction of Royal Institute of Naval Architects, 121, pp.151-165.

Ogawa, Y. Matsunami, R. and Arai, M., 2006. The effect of a bow flare shape on the water impact pressure, International Journal of Offshore and Polar Engineering (IJOPE), 16(2), pp.112-117.

Ogawa, Y., 2007. A study on nonlinear wave loads of a large container carrier in rough seas. 10th Interna-tional Symposium on Practical Design of Ships and other Floating Structures (PRADS), 1, pp.132-140.

Ogawa, Y. Takagi, K., 2009. An evaluation of whip-ping vibration utilizing the displacement potential method, $5^{\text {th }}$ International Conference on Hydroelasticity in Marine Technology, Southampton, UK, pp.213-222.

Ohmatsu, S., 1975. On the Irregular Frequencies in the Theory of Oscillating Bodies in a Free Surface, Papers of Ship Research Institute, Tokyo, Japan, 48, pp 1-13.

Oka, M., Oka, S. and Ogawa, Y., 2009. An experimental study on wave loads of a large container ship and its hydroelastic vibration, Proc. $5^{\text {th }}$ Int. Conf. Hydroelasticity in Marine Technology, Southampton, UK.

Takagi, K. and Ogawa, Y., 2007. Flow Models of the Flare Slamming. Proceedings of International Conference on Violent Flows ,pp. 173-179.

Yamamoto, Y. Fujino, M. and Fukasawa, T., 1980. Motion and longitudinal strength of a ship in head seas and the effects of nonlinearities. Journal of Society of Naval Architects of Japan, Vol. 18. pp. 91-100. 